foci, even in the absence of a structural lesion. (Sarnat HB, Flores-Sarnat L. a-B-crystallin as a tissue marker of epileptic foci in paediatric resections. Can J Neurol Sci September 2009;36:566-574). (Respond: Harvey B Sarnat, Alberta Children's Hospital, 2888 Shaganappi Trail NW, Calgary, Alberta, T3B 6A8, Canada. E-mail: Harvey.sarnat@albertahealthservices.ca).

COMMENT. Chemistry of the brain research dates back to 1884 , with the publication in London of a book by JLW Thudichum, the father of the specialty. Recognition of Neurochemistry as a specific field of research was delayed until 1955, when Elliott. Page, and Quastel, aided by many contributors, edited their classic volume, published by Charles $\mathrm{C}$ Thomas, and dedicated to the memory of Thudichum. The "chemistry of human epilepsy" was covered in a chapter by Elliott KAC of the Montreal Neurological Institute, Canada. It is fitting that the present advance in our understanding of the subject reported by the Drs Sarnat also emanates from Canada. Elliott and his co-worker, Tower, were interested in acetylcholine and the epileptic focus. Focal tissue failed to store acetylcholine in the bound, inactive form. They postulated that the abnormal activity of an epileptic focus might be a response of normal neurons to an abnormal local chemical environment. Impairments of local circulatory control around epileptogenic foci, as reported by Penfield and associates, could cause variations in local concentration of oxygen, glucose, carbon dioxide and other products of metabolism, and $\mathrm{pH}$. (Penfield WP, Erickson TC. Epilepsy and Cerebral Localization, Springfield, IL, Thomas, 1941). The present report advances our understanding of the epileptic process and demonstrates a novel immunocytochemical test for epileptogenic brain tissue, independent of the histological findings. Intense a-B-crystallin reactivity at the periphery of resected brain tissue might indicate incomplete removal of a focus and an increased risk of seizure recurrence.

\title{
CT AND MRI GUIDELINES IN RECENT-ONSET EPILEPSY
}

The International League Against Epilepsy (ILAE) Subcommittee for Pediatric Neuroimaging examined the value of, and indications for, neuroimaging in the evaluation of children with newly diagnosed epilepsy. Retrospective and prospective published series with 30 or more subjects receiving CT and MRI to evaluate new-onset seizures were reviewed. Imaging studies were abnormal in nearly $50 \%$ of children with localization-related new-onset seizures, $15-20 \%$ of imaging studies provided information on etiology and/or seizure focus, and $2-4 \%$ potentially altered immediate management. A significant imaging abnormality was almost always associated with a history of a localization-related seizure, abnormal neurologic examination, or focal EEG. Childhood absence epilepsy, juvenile absence epilepsy, juvenile myoclonic epilepsy, and benign childhood epilepsy with centrotemporal spikes were not associated with a structural imaging abnormality. Imaging is helpful in establishing seizure etiology, predicting prognosis, and in treatment. Imaging is recommended in children with new-onset localization-related epilepsy, when epilepsy classification is in doubt, and when an epilepsy syndrome with remore symptomatic cause is suspected. MRI is preferred to CT because of superior resolution, and lack of radiation. (Gaillard WD, Chiron C, Cross JH et al. for the ILAE. Guidelines for imaging infants and children with recent-onset epilepsy. Epilepsia Sept 2009;50:2147-2153). (Respond: WD Gaillard MD, Department of 
Neuroscience, Children's National Medical Center, 111 Michigan Ave NW, Washington, DC 20010. E-mail: wgaillar@,cnmc.org).

COMMENT. Imaging is most useful for children with localization-related or remote symptomatic generalized epilepsy. MRI abnormalities are more frequent in infants with seizures than in older children because of presentation of cortical malformations. The authors advise that children younger than 2 years require special MRI sequences because immature myelination may obscure the diagnosis of cortical dysplasia. If the MRI is interpreted as normal and seizures persist, repeat imaging at 6-month intervals is advised, when myelination is more mature and dysplasias can be distinguished. Gadolinium contrast is reserved for suspected tumor, vascular malformation, inflammation, and infectious disorders.

\section{LONG-TERM OUTCOME OF JUVENILE MYOCLONIC EPILEPSY}

All patients developing juvenile myoclonic epilepsy (JME) by 16 years of age in Nova Scotia between 1977 and 1985 were contacted in 2006-2008 to determine long-term seizure and social outcome, in a study at Dalhousie University, Halifax, Canada. Of 24 patients (17 women) with JME, 23 were contacted at a mean age of $36+/-4.8$ years. Age at first seizure was $10.4+/-4.3$ years. At 25-year follow-up, 11 (48\%) had discontinued AED treatment: 6 were seizure-free (without AEDs) for 5-23 years, 3 had only myoclonic seizures, and 2 had rare seizures. Of those with continued seizures, $8(36 \%)$ had episodes of convulsive status epilepticus, and 3 had intractable epilepsy. Seventy percent enjoyed satisfactory health, work, friendships, and social life, $87 \%$ graduated high school, and $69 \%$ were employed. Nine were taking antidepressants. Ten women had been pregnant and 4 men were fathers. Eleven pregnancies $(80 \%)$ were unplanned, and at least 1 unfavorable social outcome was noted in 76\%. (Camfield CS, Camfield PR. Juvenile myoclonic epilepsy 25 years after seizure onset: A population-based study. Neurology Sept 29, 2009;73:10411045). (Response and reprints: Dr Carol S Camfield, IWK Health Centre, PO Box 9700, 5850 University Ave, Halifax, Nova Scotia, Canada B3K 6R8. E-mail: camfield@,dal.ca).

COMMENT. One-third patients with JME at 25-year follow-up have seizures well controlled and AED discontinued, in contrast to the generally poor seizure outcome in previous reports. Three-quarters have experienced at least one major unfavorable social event, but $70 \%$ report satisfaction with their social life.

\section{VASCULAR DISORDERS}

\section{CEREBRAL VENOUS SINUS THROMBOSIS CASE SERIES}

Presenting features, co-morbid conditions, treatment, and outcome of cerebral venous sinus thrombosis (CVST) in a consecutive series of children are reported from Department of Paediatric Neurology, Bristol Royal Hospital for Children, UK. Twenty-one children (10 male) were diagnosed with CVST (using electronic databases and international codes) and treated in a single pediatric neurology center over a period of 8.25 years. Ages ranged from 1.4 to 16.9 years (median 7.1 years); neonates were not included. Presenting symptoms in 